\title{
Trends in site of death and health care utilization at the end of life: a population-based cohort study
}

\author{
Andrea D. Hill PhD, Therese A. Stukel PhD, Longdi Fu MSc, Damon C. Scales MD PhD, \\ Andreas Laupacis MD MSc, Gordon D. Rubenfeld MD MSc, Hannah Wunsch MD MSc, \\ James Downar MDCM MHSc, Kenneth Rockwood MD MPA, Daren K. Heyland MD MSc, \\ Samir K. Sinha MD DPhil, Camilla Zimmermann MD PhD, Sonal Gandhi MD MSc, \\ Jeff Myers MD MSEd, Heather J. Ross MD MHSc, Jean F. Kozak PhD, Scott Berry MD MHSc, \\ Shelly P. Dev MD, Ignazio La Delfa MD, Robert A. Fowler MDCM MS(Epi)
}

\section{Abstract}

Background: High rates of health care utilization at the end of life may be a marker of care that does not align with patient-stated preferences. We sought to describe trends in end-of-life care and factors associated with dying in hospital.

Methods: We conducted a population-level retrospective cohort study of adult decedents in Ontario between Apr. 1, 2004, and Mar. 31, 2015, using linked administrative data sets, including the Office of the Registrar General for Deaths database, the hospital Discharge Abstract Database, the National Ambulatory Care Reporting System and physicians' billing claims (Ontario Health Insurance Plan). The primary outcome was place of death. To determine health care utilization and health care costs during the 6 months before death, we also identified admissions to hospital and to the intensive care unit, emergency department visits, and receipt of mechanical ventilation and palliative care.

Results: In the last 6 months of life, $77.3 \%$ of 962462 decedents presented to an emergency department, $68.4 \%$ were admitted to hospital, $19.4 \%$ were admitted to an intensive care unit, and $13.9 \%$ received mechanical ventilation. Forty-five percent of all deaths occurred in hospital, a proportion that declined marginally over time, whereas receipt of palliative care increased during terminal hospital admissions (from $14.0 \%$ in fiscal year 2004/05 to $29.3 \%$ in 2014/15, $p<0.001$ ) and in the last 6 months of life (from $28.1 \%$ in $2004 / 05$ to $57.7 \%$ in $2014 / 15, p<0.001$ ). The proportion of decedents who presented to the emergency department, were admitted to hospital or were admitted to the intensive care unit in the last 6 months of life did not change over 11 years. The mean total health care costs in the last 6 months of life were highest among those dying in hospital, with most costs attributable to inpatient medical care.

Interpretation: Health care utilization in the last 6 months of life was substantial and did not decrease over time. It is possible that increased capacity for palliative, hospice and home care at the end of life may help to better align health system resources with the preferences of most patients, a topic that should be explored in future studies.

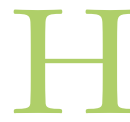
igh-quality end-of-life care is important for patients and families, and is an increasing focus for policy-makers and the research community. Although there is marked international variability in end-oflife care practices ${ }^{1-3}$ among industrialized countries, including Canada, there are high rates of in-hospital death and use of resource-intensive services, including admission to an intensive care unit (ICU). ${ }^{1}$ This resource-intensive care often does not align with patient preferences and accounts for a substantial proportion of health care expenditures. ${ }^{4-6}$

Earlier reports emphasized gaps in the provision of quality end-of-life care for dying Canadians and their families, ${ }^{7,8}$ including marked variability in the provision of palliative care services. 9 Amid a rapidly aging Canadian population and the accompanying large increase in the prevalence of chronic diseases and frailty, whether and to what extent these gaps remain
Competing interests: James Downar has received speaker's fees from Boehringer-Ingelheim (Canada) and Novartis, as well as personal fees from the Ontario College of Family Physicians for participation on a steering committee for end-of-life care. Kenneth Rockwood is the founder and chief scientific officer of DGI Clinical, which works with various pharmaceutical companies to develop individualized outcome measurement and advanced data analytics. DGI Clinical is supported by the NRC's Industrial Research Assistance Program. Dr. Rockwood has asserted copyright in the Clinical Frailty Scale (through Dalhousie University's Industry Liaison Office), which is available free for use in education, research and not-for-profit health care. He has also received personal fees from various pharmaceutical companies for activities unrelated to this study. No other competing interests were declared.

This article has been peer reviewed.

Correspondence to: Andrea Hill, Andrea.Hill @sunnybrook.ca

CMAJ Open 2019. DOI:10.9778/cmajo.20180097 
is largely unknown. Measuring trends and current health care practices at the end of life is important to better align patient preferences and health needs with health system resources and policies. However, estimates of temporal trends in the use of health care resources at the end of life are conflicting. For example, some studies suggest that rates of hospital death are declining, ${ }^{10,11}$ whereas others do not. ${ }^{12,13}$ In Canada, analyses between 1994 and 2004 found decreasing rates of hospital deaths; ${ }^{10}$ however, whether this trend has continued or how it applies to other markers of end-of-life care is unclear.

We sought to describe contemporary temporal patterns in place of death, heath care utilization and costs at the end of life and to identify factors associated with dying in a hospital in Ontario.

\section{Methods}

\section{Design and settings}

We conducted a population-based cohort study in Ontario, Canada's largest province (population 13.6 million, of whom about $16 \%$ are 65 years or older). Most physician and hospital services are universally insured for all residents of Ontario, through the province's single-payer, publicly funded health care system, with health services planning and delivery coordinated by the province's 14 regional Local Health Integration Networks (LHINs).

We identified individuals 18 years of age or older who died between Apr. 1, 2004, and Mar. 31, 2015 (fiscal years 2004 to 2014), using the Registered Persons Database, which contains vital statistics data on all residents of Ontario, including date of and age at death. We used the Office of the Registrar General for Deaths database to identify the cause of death. To describe health care utilization and costs before death, we linked information on decedents to population-based health administrative data sets. These data sets included the Canadian Institute for Health Information's Discharge Abstract Database, which captures data on all acute care hospital admissions in Ontario; the National Ambulatory Care Reporting System, which contains information on hospitalbased ambulatory services, including emergency department visits, day surgery and outpatient clinic visits; the Continuing Care Reporting System, which includes demographic and clinical information on individuals receiving facility-based continuing care services; and the Home Care Database, which captures data on receipt of publicly funded home care services, including date and type of services. Information on physician services, including date and type of medical services provided and billing claims for inpatient and outpatient services, was obtained from the Ontario Health Insurance Plan (OHIP) database. These data sets were linked using unique encoded identifiers and were analyzed at ICES.

\section{Baseline characteristics}

Decedents' demographic characteristics, including age, sex, income, location of residence and cause of death, were measured at the time of death. Income (ascribed as neighbourhood income quintile) and urban or rural residence were determined by linking each decedent's residential postal code at the time of death to the Statistics Canada 2006 census. Cause of death was determined from the Office of the Registrar General for Deaths database and classified according to the International Statistical Classification of Diseases and Related Health Problems, 10th revision (ICD-10). A primary chronic condition was defined according to a 9-level variable indicating the presence of cancer, chronic obstructive pulmonary disease (COPD), coronary artery disease, congestive heart failure, peripheral vascular disease, severe liver disease, diabetes with end organ failure, renal failure or dementia. ${ }^{14}$ Decedents were assigned to one of these conditions on the basis of ICD-10 diagnostic codes during the last hospitalization, which were available for more than $90 \%$ of decedents. When multiple chronic conditions were identified, the following hierarchy was applied: most responsible diagnosis, then comorbid diagnoses, then minor diagnoses.

For each LHIN, we determined the number of acute care beds per 100000 population and calculated the median bed capacity for the province over the study period. We classified LHINs falling below and above the provincial median for acute care beds as having "low acute care bed capacity" and "high acute care bed capacity," respectively, and categorized decedents according to the acute care bed capacity of their LHIN.

\section{Outcomes}

Our primary outcome was place of death, classified as a hospital, the patient's home, a long-term care facility or another location. Deaths in hospital were further classified according to whether they occurred in an ICU or another location. Secondary outcomes were the factors associated with dying in hospital, the use of health services during the 6 months before death (including acute care hospitalizations and emergency department admissions, receipt of mechanical ventilation and palliative care, and number of physician visits) and health care costs.

We classified place of death using information contained in the vital statistics (Registered Persons Database), hospital (Discharge Abstract Database) and emergency department (National Ambulatory Care Reporting System) databases. For decedents who were admitted to hospital within the 6 months before death, we identified the number of admissions to an ICU using special care unit codes in the Discharge Abstract Database. ${ }^{15,16} \mathrm{We}$ also measured the total number of inpatient and ICU days for these individuals. We identified receipt of palliative care using a comprehensive set of diagnostic and billing codes across multiple providers and health care settings, including information contained in the home care (Home Care Database), hospital (Discharge Abstract Database), emergency department (National Ambulatory Care Reporting System), long-term care and complex continuing care (Continuing Care Reporting System) and physician billing (OHIP) databases, consistent with prior studies. ${ }^{17,18}$

We estimated health care costs (from the perspective of the health care payer, the Ontario Ministry of Health and Longterm Care) from the health administrative data sets using an established approach for person-level costing. ${ }^{19,20}$ This algorithm summarizes costs attributed to several health sectors, 
for example, inpatient acute care, emergency department visits, complex continuing care and physician services (for details, see Appendix 1, available at www.cmajopen.ca/ content/7/2/E306/supp1/DC1). Briefly, we derived costs for institutional care (e.g., hospital and rehabilitation admissions) by applying resource intensity weights for the specific care sector to the cost per weighted case determined from amounts paid by the Ontario Ministry of Health and Long-term Care. Costs for health services associated with specific fees (e.g., physician visits, diagnostic tests, medications) were based directly on the fee paid per use of these services. ${ }^{19}$ All costs were adjusted to 2014 Canadian dollars.

\section{Statistical analyses}

We used descriptive statistics to characterize the location of death and the use of health services for all decedents and according to groups defined by age, chronic condition and year of death. We summarized categorical and continuous variables as proportions and means (standard deviations [SDs]) or medians (interquartile ranges [IQRs]), respectively. Because of our large sample size and the potential for small differences to be statistically significant, we do not report $p$ values for group comparisons. We compared the characteristics of individuals who died in hospital and out of hospital using standardized differences, where a difference less than 0.1 is commonly used to indicate negligible differences between groups. ${ }^{21}$ To summarize differences in health care resource use between groups and over time (fiscal year $2004 \mathrm{v}$. fiscal year 2014), we calculated absolute differences (with $95 \%$ confidence intervals [CIs]). We used the Cochran-Armitage trend test to examine changes over time in the location of death. We used multilevel logistic regression, accounting for the clustering of decedents within LHINs, to identify factors associated with dying in hospital. We considered putative factors on the basis of their clinical relevance and availability in the data set. At the patient level, these factors were age, sex, Charlson comorbidity score, rural residence, income, year and cause of death. The LHIN acute care bed capacity was included as a region-level factor. All analyses were conducted using SAS Enterprise Guide 7.1 (SAS Institute).

\section{Ethics approval}

This study was approved by the institutional review board at Sunnybrook Health Sciences Centre, Toronto, Ontario.

\section{Results}

\section{Patterns and temporal trends in place of death and use of palliative care}

There were 962462 decedents in Ontario between fiscal year 2004 and fiscal year 2014. The mean age at death was 76.3 (SD 14.8) years, and $50.1 \%$ of decedents were women (Table 1). Overall, $45.0 \%$ of decedents died in hospital. The proportion who died in hospital declined only slightly over time $(45.9 \%$ in fiscal year 2004 and $43.2 \%$ in fiscal year 2014; absolute difference $2.7 \%, 95 \%$ CI $2.3 \%$ to $3.2 \%$; test for trend $p<0.001$; Figure 1), with a corresponding increase in deaths at home $37.9 \%$ and $43.2 \%$, respectively; absolute difference $5.3 \%, 95 \%$ CI $4.9 \%$ to $5.8 \%$; test for trend $p<$ 0.001; Figure 1). Patterns in place of death varied according to the primary chronic condition, with those who had liver disease $(73.3 \%)$, peripheral vascular disease $(67.5 \%)$, congestive heart failure $(61.1 \%)$, COPD $(60.8 \%)$, coronary artery disease $(57.7 \%)$ and cancer $(54.0 \%)$ being more likely to die in hospital than those who had dementia (34.2\%) (absolute differences ranging from $19.8 \%$ [ $95 \%$ CI $19.4 \%$ to $20.2 \%$ ] to $39.1 \%$ [ $95 \%$ CI $38.3 \%$ to $39.8 \%$ ]; see Figure A1 in Appendix 2, available at www.cmajopen.ca/content/7/2/ E306/suppl/DC1).

The proportion of decedents who received palliative care during the terminal hospital admission more than doubled, from $14.0 \%$ in fiscal year 2004 to $29.3 \%$ in fiscal year 2014 (absolute difference $15.3 \%$, 95\% CI $14.9 \%$ to $15.7 \%$; Figure 1). Decedents with cancer had the highest rates of palliative care during the terminal hospitalization throughout the study $37.9 \%$ in fiscal year 2004 to $44.0 \%$ in fiscal year 2014; absolute difference $6.1 \%, 95 \%$ CI $5.2 \%$ to $7.1 \%$ ), but increased uptake of palliative care was observed for patients with all conditions, including those with dementia $(7.9 \%$ in fiscal year 2004 to $23.7 \%$ in fiscal year 2014; absolute difference $15.8 \%, 95 \%$ CI $14.7 \%$ to $16.8 \%$ ), coronary artery disease $(7.6 \%$ in fiscal year 2004 to $25.6 \%$ in fiscal year 2014 ; absolute difference $18.0 \%, 95 \%$ CI $16.4 \%$ to $19.6 \%$ ) and congestive heart failure (10.3\% in fiscal year 2004 to $35.3 \%$ in fiscal year 2014; absolute difference $25.0 \%$, $95 \%$ CI $24.0 \%$ to 26.2\%) (see Figure A1 in Appendix 2). When the analysis was restricted to decedents who died in hospital, receipt of palliative care during the terminal hospital admission increased significantly, from $30.5 \%$ in fiscal year 2004 to $67.9 \%$ in fiscal year 2014 (absolute difference 37.4\%, 95\% CI 36.8\% to $38.1 \%)$. Similar increases were observed among patients who had chronic conditions, with decedents who had cancer having among the highest rates of palliative care during the terminal hospital admission (see Figure A2 in Appendix 2).

For the adjusted analysis, it was necessary to recut the data in the course of responding to requests from the reviewers and editors; by the time of this re-analysis, there had been updates to the project data sources and an additional 21 decedents were included. In this adjusted analysis, men and older decedents were more likely to die in hospital than out of hospital (Table 2), with the association between age and death in hospital attenuating among those 85 years of age and older. In addition, the odds of dying in hospital were higher for those residing in more rural areas (odds ratio [OR] 1.12, 95\% CI 1.11 to 1.13 ) and neighbourhoods with the lowest (compared with the highest) income quintile (OR 1.13, 95\% CI 1.12 to 1.14). There was no difference in the odds of in-hospital death among decedents living in LHINs with high and low acute care bed capacity (Table 2 ).

\section{Decedents' use of health care resources in last 6 months of life}

The majority of decedents visited the emergency department (77.3\%) and saw 10 or more physicians (52.6\%) during the last 


\begin{tabular}{|c|c|c|c|c|}
\hline \multirow[b]{2}{*}{ Characteristic } & \multicolumn{3}{|c|}{ Location of death; \% of decedents* } & \multirow[b]{2}{*}{$\begin{array}{c}\text { Standardized } \\
\text { difference }\end{array}$} \\
\hline & $\begin{array}{l}\text { All locations } \\
n=962462\end{array}$ & $\begin{array}{c}\text { In hospital } \\
n=433074\end{array}$ & $\begin{array}{c}\text { Out of hospital } \\
n=529388 \dagger\end{array}$ & \\
\hline Age at death, yr, mean \pm SD & $76.3 \pm 14.8$ & $75.8 \pm 13.5$ & $76.6 \pm 15.8$ & 0.06 \\
\hline \multicolumn{5}{|l|}{ Age category at death, yr } \\
\hline $18-49$ & 5.8 & 4.6 & 6.8 & 0.10 \\
\hline $50-54$ & 3.4 & 3.3 & 3.5 & 0.01 \\
\hline $55-59$ & 4.7 & 4.7 & 4.6 & 0.01 \\
\hline $60-64$ & 6.0 & 6.4 & 5.6 & 0.03 \\
\hline $65-69$ & 7.4 & 8.3 & 6.6 & 0.07 \\
\hline $70-74$ & 9.5 & 11.0 & 8.3 & 0.09 \\
\hline $75-79$ & 12.8 & 14.7 & 11.4 & 0.10 \\
\hline $80-84$ & 16.6 & 17.9 & 15.6 & 0.06 \\
\hline$\geq 85$ & 33.7 & 28.9 & 37.6 & 0.18 \\
\hline Sex, female & 50.1 & 48.0 & 51.9 & 0.08 \\
\hline \multicolumn{5}{|l|}{ Charlson Comorbidity Index score } \\
\hline 0 & 14.1 & 6.5 & 20.4 & 0.42 \\
\hline 1 & 13.9 & 14.3 & 13.5 & 0.02 \\
\hline$\geq 2$ & 61.7 & 79.2 & 47.3 & 0.70 \\
\hline Missing & 10.3 & 0 & 18.7 & NA \\
\hline \multicolumn{5}{|l|}{ Income quintile§ } \\
\hline 1 (lowest) & 23.5 & 23.8 & 23.3 & 0.02 \\
\hline 2 & 21.1 & 21.9 & 20.4 & 0.04 \\
\hline 3 & 19.1 & 19.2 & 19.0 & 0 \\
\hline 4 & 18.5 & 18.2 & 18.8 & 0.02 \\
\hline 5 (highest) & 17.8 & 16.9 & 18.5 & 0.04 \\
\hline Rural residence§ & 14.8 & 15.3 & 14.5 & 0.02 \\
\hline \multicolumn{5}{|l|}{ Chronic conditions } \\
\hline Cancer & 20.3 & 24.4 & 17.0 & 0.18 \\
\hline Congestive heart failure & 11.5 & 15.6 & 8.1 & 0.23 \\
\hline Dementia & 9.0 & 6.9 & 10.8 & 0.14 \\
\hline COPD & 5.1 & 6.9 & 3.6 & 0.15 \\
\hline Coronary artery disease & 4.7 & 6.1 & 3.6 & 0.11 \\
\hline Renal failure & 3.0 & 4.1 & 2.1 & 0.12 \\
\hline Severe liver disease & 1.5 & 2.5 & 0.7 & 0.14 \\
\hline Peripheral vascular disease & 1.0 & 1.5 & 0.6 & 0.09 \\
\hline Diabetes with end-organ damage & 0.1 & 0.1 & 0.1 & 0 \\
\hline None & 43.8 & 32.1 & 53.3 & 0.44 \\
\hline \multicolumn{5}{|l|}{ Cause of death (top 20) } \\
\hline Ischemic heart disease & 13.6 & 9.9 & 16.7 & 0.20 \\
\hline \multicolumn{5}{|l|}{ Cancer } \\
\hline Lung & 6.2 & 7.1 & 5.5 & 0.06 \\
\hline Colorectal & 3.0 & 3.0 & 2.9 & 0.01 \\
\hline Hematologic & 2.5 & 3.5 & 1.6 & 0.12 \\
\hline Breast & 1.8 & 1.8 & 1.8 & 0 \\
\hline
\end{tabular}




\begin{tabular}{|c|c|c|c|c|}
\hline \multirow[b]{2}{*}{ Characteristic } & \multicolumn{3}{|c|}{ Location of death; $\%$ of decedents ${ }^{*}$} & \multirow[b]{2}{*}{$\begin{array}{c}\text { Standardized } \\
\text { difference }\end{array}$} \\
\hline & $\begin{array}{l}\text { All locations } \\
n=962462\end{array}$ & $\begin{array}{c}\text { In hospital } \\
n=433074\end{array}$ & $\begin{array}{l}\text { Out of hospital } \\
n=529388 \dagger\end{array}$ & \\
\hline Prostate & 1.4 & 1.2 & 1.5 & 0.02 \\
\hline Pancreas & 1.4 & 1.4 & 1.4 & 0 \\
\hline Dementia and Alzheimer disease & 5.9 & 2.5 & 8.7 & 0.27 \\
\hline Cerebrovascular disease & 5.1 & 6.0 & 4.3 & 0.08 \\
\hline Chronic lower respiratory disease & 3.5 & 4.1 & 3.0 & 0.06 \\
\hline Diabetes mellitus & 2.8 & 2.2 & 3.4 & 0.07 \\
\hline Influenza and pneumonia & 2.2 & 3.0 & 1.5 & 0.10 \\
\hline Diseases of urinary system & 2.0 & 2.8 & 1.3 & 0.11 \\
\hline Falls & 1.6 & 2.4 & 1.0 & 0.11 \\
\hline Heart failure and complications & 1.6 & 1.7 & 1.5 & 0.02 \\
\hline Cirrhosis and other liver disease & 1.2 & 1.9 & 0.7 & 0.11 \\
\hline Hypertensive disease & 1.0 & 0.6 & 1.4 & 0.08 \\
\hline Intentional self-harm & 1.0 & 0.2 & 1.6 & 0.16 \\
\hline Cardiac arrhythmias & 1.0 & 1.2 & 0.8 & 0.04 \\
\hline Sepsis & 0.9 & 1.6 & 0.3 & 0.13 \\
\hline \multicolumn{5}{|c|}{$\begin{array}{l}\text { Note: COPD = chronic obstructive pulmonary disease, NA = not applicable, SD = standard deviation. } \\
\text { *Except where indicated otherwise. } \\
\text { tOut-of-hospital deaths occurred in the home ( } n=389250) \text {, in long-term care facilities }(n=77280) \text { and in other locations }(n=62858) \text {. } \\
\text { fStandardized differences for comparisons by location of death, where a difference less than } 0.1 \text { is commonly deemed to indicate } \\
\text { negligible differences between groups. } \\
\text { \$Information on income and location of residence was missing for } 0.5 \%(5213) \text { and } 0.1 \%(617) \text { of decedents, respectively. }\end{array}$} \\
\hline
\end{tabular}

6 months of life (Table 3). In the same period, $68.4 \%$ were admitted to hospital at least once (median number of hospitalizations 1 , IQR 0 to 2), about 1 in every 5 decedents was admitted to an ICU, and $13.9 \%$ received mechanical ventilation. Decedents spent a median of 6 (IQR 0 to 19) days in hospital during the last 6 months of life. Over the 11-year study period, there was no substantial change in the proportion of decedents who were admitted to hospital or the ICU or who used emergency department services in the last 6 months of life. There was, however, an increasing trend in the proportion of decedents seeing 10 or more physicians and receiving mechanical ventilation in the 6 months before death (Table 3 ).

Rates of health service use during the last 6 months of life were higher among decedents who died in hospital than among those who died in other locations, including a higher proportion of admissions to the ICU (36.3\% v. $5.6 \%$; absolute difference $30.7 \%, 95 \%$ CI $30.6 \%$ to $30.9 \%$ ) and a higher proportion receiving mechanical ventilation $(27.7 \%$ v. $2.6 \%$; absolute difference $25.1 \%$, $95 \%$ CI $25.0 \%$ to $25.2 \%$ ). Among individuals who died in hospital, rates of use of these high-intensity resources (ICU and mechanical ventilation) were lower among those who received palliative care within the last 6 months of life (Table 4). Compared with decedents who had a chronic organ failure-related condition (e.g., COPD, congestive heart failure), those who had cancer or dementia were less likely to be admitted to the ICU and less likely to receive mechanical ventilation (see Table A1 in Appendix 3, available at www.cmajopen. $\mathrm{ca} /$ content/7/2/E306/suppl/DC1). About half of decedents received palliative care services during the last 6 months of life, with use of these services increasing significantly over the study period (from $28.1 \%$ in fiscal year 2004 to $57.7 \%$ in fiscal year 2014; absolute difference $29.6 \%$, $95 \%$ CI $29.2 \%$ to $30.1 \%$ ) (Figure 2). Across all years, receipt of palliative care during the last 6 months of life was highest among decedents dying in a long-term care facility, ranging from $61.9 \%$ in fiscal year 2004 to $88.3 \%$ in fiscal year 2014 (absolute difference $26.4 \%$, 95\% CI $25.1 \%$ to $27.8 \%$ ) (Figure 2).

\section{Health care costs in the last 6 months of life}

Median total health care costs in the last 6 months of life were higher among decedents who died in hospital (\$32 291, IQR $\$ 18245$ to $\$ 55308$ ) than among those who died out of hospital (\$22 895, IQR \$7636 to \$36 931) (see Table A2 in Appendix 3). Overall, most non-patient-borne health care costs were attributed to acute care inpatient costs, which ranged from a median of \$0 (IQR \$0 to \$11 060) among decedents who died in settings other than a hospital to \$16 284 (IQR \$7290 to $\$ 33$ 216) among those dying in hospital.

\section{Interpretation}

In this population-based study, we found that nearly half of all deaths occurred in hospital, with one-quarter of these deaths occurring in the ICU. We also found substantial health care 


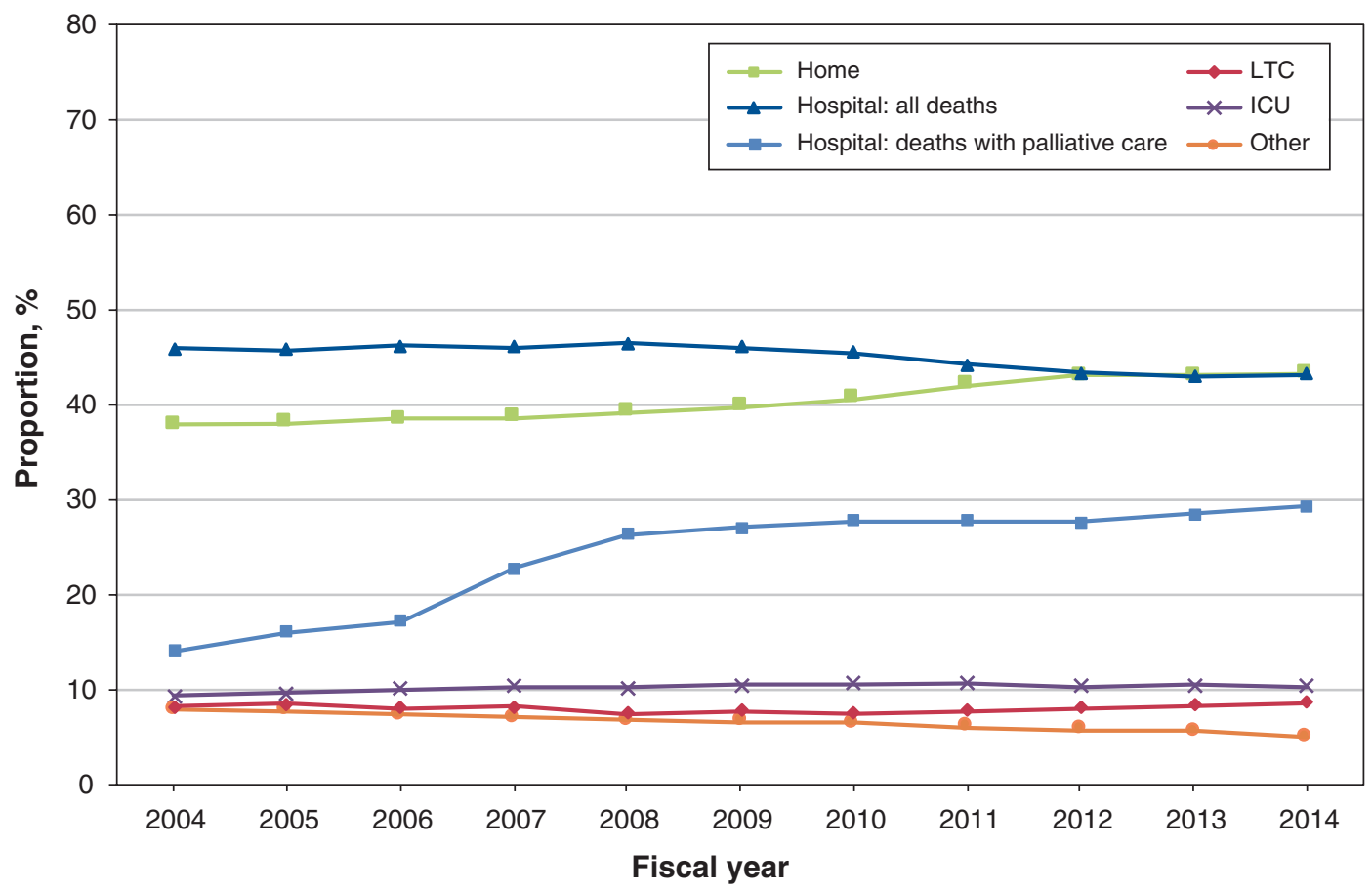

Figure 1: Temporal trends in location of death for Ontario, from Apr. 1, 2004, to Mar. 31, 2015 (fiscal year 2004 to fiscal year 2014). Note: ICU = intensive care unit, LTC = long-term care.

utilization among decedents in the 6 months before death. For example, 3 of every 4 decedents were admitted to a hospital or emergency department. Between fiscal years 2004 and 2014, deaths in hospital decreased, with concomitant increases in the proportions of terminal hospitalizations involving palliative care and deaths at home; however, other markers of acute care and use of hospital-based health care resources did not change.

Like others, ${ }^{1-3,22,23}$ we found considerable use of acute care health resources at or near the time of death. Overall, these findings suggest a continued reliance on hospitals to provide end-of-life care and underscore the gaps in options for palliative, hospice or home-based care at the end of life within the Canadian health care system..$^{7-9,24}$ A lack of outpatient structures and processes for delivering end-of-life services, including comprehensive palliative care services, may therefore help to explain the observed utilization patterns, especially in more rural and remote areas. Further research is needed to establish whether, and which models of, palliative care service are effective in reducing the use of acute care health resources by individuals who are dying.

In our study, we observed temporal trends in markers of end-of-life care practices, notably decreasing rates of in-hospital deaths and increasing receipt of palliative care. From 1980 to 1997 , more than $66 \%$ of Ontarians died in hospital, with relatively stable rates over that period. ${ }^{25}$ Although methodological differences partly explain the substantial drop in deaths occurring in hospital between that earlier report and the findings of the current study, the change (from $66 \%$ to $45 \%$ ) may also have been related to substantial health care restructuring efforts in Ontario, which resulted in the closure of thousands of hospital beds and the creation of new long-term care beds. ${ }^{26}$ Nonetheless, that almost half of decedents received some form of palliative care in the last 6 months of life is encouraging and generally similar to recent observations using comparable methods. ${ }^{17,18} \mathrm{We}$ extend these earlier findings by providing evidence of an increasing trend in the receipt of palliative care at the population level. This trend is important, as our finding likely reflects increasing recognition of the benefits of palliative care for improving care at the end of life and the growth of palliative care services in the last decade. ${ }^{27-31}$ It is also plausible that shifting awareness regarding palliative care services among individuals who are dying and their caregivers might have influenced end-of-life care decisions. Future studies aimed at understanding the drivers of the observed increase will be informative to efforts to improve care at the end of life.

Our finding that individuals dying in hospital had higher costs of care in the last 6 months of life and that about $50 \%$ of these costs were attributable to inpatient care align with previous data from Ontario. ${ }^{32}$ Although we do not propose that all such admissions can or should be avoided, given the challenges of predicting death, ${ }^{33}$ these data suggest that there may be opportunities to improve end-of-life care that is better aligned with patients' wishes. In particular, the observed higher risk of dying in hospital among individuals from rural residences and lower-income neighbourhoods may indicate 
Table 2 (part 1 of 2): Multilevel model of factors associated with dying in hospital versus all other locations*

\begin{tabular}{|c|c|c|}
\hline \multirow[b]{2}{*}{ Factor } & \multicolumn{2}{|c|}{ OR $(95 \% \mathrm{Cl})$} \\
\hline & Unadjusted† & Adjusted \\
\hline \multicolumn{3}{|l|}{ Patient-related } \\
\hline \multicolumn{3}{|l|}{ Age category, yr } \\
\hline $18-49$ & 1.0 (Ref.) & 1.0 (Ref.) \\
\hline $50-54$ & $1.40(1.36$ to 1.44$)$ & $1.34(1.30$ to 1.38$)$ \\
\hline $55-59$ & 1.54 (1.50 to 1.58$)$ & 1.47 (1.43 to 1.51$)$ \\
\hline $60-64$ & $1.70(1.66$ to 1.74$)$ & $1.63(1.59$ to 1.67$)$ \\
\hline $65-69$ & 1.88 (1.84 to 1.92$)$ & $1.80(1.76$ to 1.84$)$ \\
\hline $70-74$ & 1.98 (1.94 to 2.03$)$ & 1.91 (1.86 to 1.95$)$ \\
\hline $75-79$ & $1.92(1.88$ to 1.96$)$ & 1.89 (1.85 to 1.93$)$ \\
\hline $80-84$ & $1.71(1.68$ to 1.74$)$ & $1.74(1.70$ to 1.78$)$ \\
\hline$\geq 85$ & 1.15 (1.13 to 1.17$)$ & $1.22(1.20$ to 1.25$)$ \\
\hline \multicolumn{3}{|l|}{ Sex } \\
\hline Men & 1.0 (Ref.) & 1.0 (Ref.) \\
\hline Women & 0.86 (0.85 to 0.86$)$ & 0.88 (0.87 to 0.89$)$ \\
\hline \multicolumn{3}{|l|}{ Income quintile } \\
\hline 1 (lowest) & 1.0 (Ref.) & 1.0 (Ref.) \\
\hline 2 & 1.04 (1.03 to 1.05$)$ & $1.02(1.01$ to 1.04$)$ \\
\hline 3 & $0.96(0.95$ to 0.98$)$ & 0.96 (0.94 to 0.97$)$ \\
\hline 4 & $0.93(0.92$ to 0.94$)$ & $0.92(0.91$ to 0.93$)$ \\
\hline 5 (highest) & 0.89 (0.88 to 0.90$)$ & 0.88 (0.88 to 0.89$)$ \\
\hline \multicolumn{3}{|l|}{ Rural residence } \\
\hline No & 1.0 (Ref.) & 1.0 (Ref.) \\
\hline Yes & $1.13(1.11$ to 1.14$)$ & $1.12(1.11$ to 1.13$)$ \\
\hline \multicolumn{3}{|l|}{ Cause of death } \\
\hline $\begin{array}{l}\text { Ischemic heart } \\
\text { disease }\end{array}$ & 1.0 (Ref.) & 1.0 (Ref.) \\
\hline \multicolumn{3}{|l|}{ Cancer } \\
\hline Lung & 2.16 (2.12 to 2.21$)$ & 2.00 (1.96 to 2.04$)$ \\
\hline Colorectal & $1.76(1.72$ to 1.81$)$ & 1.71 (1.66 to 1.75$)$ \\
\hline Hematologic & 3.59 (3.48 to 3.69$)$ & 3.51 (3.41 to 3.61$)$ \\
\hline Breast & 1.65 (1.60 to 1.71$)$ & 1.79 (1.73 to 1.85$)$ \\
\hline Prostate & $1.43(1.38$ to 1.48$)$ & 1.31 (1.26 to 1.36$)$ \\
\hline Pancreas & 1.66 (1.60 to 1.72$)$ & $1.60(1.54$ to 1.66$)$ \\
\hline $\begin{array}{l}\text { Dementia and } \\
\text { Alzheimer disease }\end{array}$ & $0.48(0.47$ to 0.50$)$ & 0.55 (0.54 to 0.56$)$ \\
\hline $\begin{array}{l}\text { Cerebrovascular } \\
\text { disease }\end{array}$ & 2.35 (2.30 to 2.40$)$ & 2.48 (2.43 to 2.53 ) \\
\hline $\begin{array}{l}\text { Chronic lower } \\
\text { respiratory disease }\end{array}$ & 2.31 (2.25 to 2.37$)$ & 2.28 (2.22 to 2.34$)$ \\
\hline Diabetes mellitus & $1.08(1.05$ to 1.11$)$ & 1.06 (1.03 to 1.09$)$ \\
\hline Influenza, pneumonia & 3.35 (3.25 to 3.45 ) & 3.72 (3.61 to 3.83 ) \\
\hline $\begin{array}{l}\text { Diseases of urinary } \\
\text { system }\end{array}$ & 3.60 (3.49 to 3.72$)$ & 3.84 (3.72 to 3.97 ) \\
\hline Falls & 4.21 (4.07 to 4.37 ) & 4.67 (4.50 to 4.84$)$ \\
\hline
\end{tabular}

Table 2 (part 2 of 2): Multilevel model of factors associated with dying in hospital versus all other locations*

\section{OR $(95 \% \mathrm{Cl})$}

\begin{tabular}{|lcc|}
\cline { 2 - 3 } Factor & \multicolumn{1}{c}{ Unadjusted $\dagger$} & Adjusted \\
\hline Heart failure & $1.92(1.85$ to 1.98$)$ & $2.09(2.02$ to 2.17$)$ \\
\hline $\begin{array}{l}\text { Cirrhosis and other } \\
\text { liver diseases }\end{array}$ & $4.65(4.47$ to 4.85$)$ & $4.64(4.45$ to 4.83$)$ \\
\hline $\begin{array}{l}\text { Hypertensive } \\
\text { disease }\end{array}$ & $0.75(0.72$ to 0.79$)$ & $0.82(0.79$ to 0.86$)$ \\
\hline $\begin{array}{l}\text { Intentional self-harm } \\
\text { Cardiac arrhythmias }\end{array}$ & $0.16(0.15$ to 0.18$)$ & $0.19(0.18$ to 0.21$)$ \\
\hline Sepsis & $2.66(2.55$ to 2.78$)$ & $2.94(2.82$ to 3.07$)$ \\
\hline Yearł & $8.90(8.42$ to 9.41$)$ & $9.29(8.78$ to 9.82$)$ \\
\hline
\end{tabular}

\section{LHIN-related}

Acute care bed capacity§

$\begin{array}{ccc}\text { Low } & 1.0 \text { (Ref.) } & 1.0 \text { (Ref.) } \\ \text { High } & 1.00(0.97 \text { to } 1.03) & 1.02(1.00 \text { to } 1.05)\end{array}$

Note: $\mathrm{Cl}=$ confidence interval, LHIN = Local Health Integration Network, OR = odds ratio, Ref. = reference category.

*The sample size of 962483 for this analysis reflects multilevel models performed on Oct. 25, 2018.

†Accounts for clustering by LHIN.

†ORs reflect per 10-year unit change.

$\S$ Defined using the median bed capacity per 100000 population for the province over the study period. LHINs falling below and above the provincial median were classified as having "low acute care bed capacity" and "high acute care bed capacity", respectively.

disparities in access to end-of-life care services, including availability of home, palliative and hospice care. Further, although our data are unable to provide insights regarding the appropriateness of care, the observation that a large proportion of decedents received care from 10 or more physicians within the last 6 months of life raises concerns about the potential for fragmented care. Care continuity may be important not only in terms of the quality of care provided to these individuals, but inadequacies may also adversely affect health care costs. ${ }^{34}$

Our findings suggest important differences in care depending upon predominant terminal clinical diagnoses. For example, there were higher rates of ICU admission, receipt of mechanical ventilation in the period before death and hospital-based deaths among those with organ failure (e.g., congestive heart failure, COPD, coronary artery disease, liver failure, renal failure) than among those with cancer or dementia. This finding has implications for planning health services, supporting individuals dying from chronic non-cancer conditions and potentially supporting subspecialist clinicians treating those conditions. Having greater options for end-of-life and palliative care in the community setting or in hospice may increase quality-adjusted life-days, and may reduce both hospitalization rates and overall costs..$^{22,35-37}$ This is particularly relevant for individuals dying with non-cancer conditions, for whom options for palliative care within the Canadian setting are limited. ${ }^{38}$ 


\begin{tabular}{|c|c|c|c|c|c|c|c|}
\hline \multirow[b]{2}{*}{ Fiscal year } & \multicolumn{7}{|c|}{ Health care service utilized; $\%$ of patients ${ }^{*}$} \\
\hline & $\begin{array}{l}\text { Hospital } \\
\text { admission }\end{array}$ & $\begin{array}{l}\text { Hospital days, } \\
\text { median (IQR) }\end{array}$ & $\begin{array}{c}\text { ICU } \\
\text { admission }\end{array}$ & $\begin{array}{l}\text { ICU days, } \uparrow \\
\text { mean } \pm \text { SD }\end{array}$ & $\begin{array}{l}\text { ED } \\
\text { visits }\end{array}$ & $\begin{array}{l}\text { Saw } \geq 10 \\
\text { physicians }\end{array}$ & $\begin{array}{l}\text { Mechanical } \\
\text { ventilation }\end{array}$ \\
\hline All & 68.4 & $6(0$ to 19$)$ & 19.4 & $1.7 \pm 6.5$ & 77.3 & 52.6 & 13.9 \\
\hline 2004 & 68.7 & $6(0$ to 20$)$ & 19.1 & $1.5 \pm 6.1$ & 76.4 & 44.8 & 12.3 \\
\hline 2005 & 68.8 & $6(0$ to 20$)$ & 19.2 & $1.6 \pm 6.5$ & 77.1 & 45.9 & 12.6 \\
\hline 2006 & 68.2 & $6(0$ to 20$)$ & 19.1 & $1.6 \pm 6.2$ & 77.1 & 48.7 & 13.2 \\
\hline 2007 & 68.4 & $6(0$ to 20$)$ & 19.3 & $1.6 \pm 6.3$ & 77.2 & 51.3 & 13.6 \\
\hline 2008 & 68.2 & $6(0$ to 20$)$ & 18.6 & $1.6 \pm 6.4$ & 77.0 & 52.2 & 13.5 \\
\hline 2009 & 68.6 & $6(0$ to 19$)$ & 19.5 & $1.7 \pm 6.9$ & 77.2 & 53.8 & 14.3 \\
\hline 2010 & 68.5 & $6(0$ to 19$)$ & 19.2 & $1.7 \pm 6.4$ & 77.6 & 54.8 & 14.3 \\
\hline 2011 & 68.5 & $6(0$ to 19$)$ & 19.5 & $1.8 \pm 6.9$ & 77.7 & 55.7 & 14.3 \\
\hline 2012 & 67.9 & $6(0$ to 19$)$ & 19.7 & $1.7 \pm 6.6$ & 77.2 & 55.1 & 14.5 \\
\hline 2013 & 68.5 & $6(0$ to 19$)$ & 20.1 & $1.8 \pm 6.8$ & 77.7 & 57.1 & 15.1 \\
\hline 2014 & 68.6 & $6(0$ to 18$)$ & 19.9 & $1.8 \pm 6.7$ & 77.9 & 57.5 & 15.1 \\
\hline $\begin{array}{l}\text { Absolute difference, \% } \\
(95 \% \mathrm{Cl}) \ddagger\end{array}$ & $\begin{array}{c}0 \\
(-0.5 \text { to } 0.4)\end{array}$ & NA & $\begin{array}{c}0.7 \\
(0.4 \text { to } 1.1)\end{array}$ & $\begin{array}{c}0.3 \\
(0.2 \text { to } 0.4)\end{array}$ & $\begin{array}{c}1.5 \\
(1.1 \text { to } 1.9)\end{array}$ & $\begin{array}{c}12.6 \\
(12.2 \text { to } 13.1)\end{array}$ & $\begin{array}{c}2.8 \\
\text { (2.5 to } 3.1)\end{array}$ \\
\hline \multicolumn{8}{|c|}{$\begin{array}{l}\text { Note: } \mathrm{Cl}=\text { confidence interval, } \mathrm{ED}=\text { emergency department, ICU = intensive care unit. IQR = interquartile range, NA = not applicable, SD = standard deviation. } \\
\text { *Except where indicated otherwise. } \\
\text { tFor all years, the median number of ICU days was } 0 \text {. } \\
\text { fThe absolute difference, calculated by subtraction, compares utilization of each health care service between fiscal year } 2004 \text { and fiscal year } 2014 .\end{array}$} \\
\hline
\end{tabular}

\begin{tabular}{|c|c|c|c|c|c|c|c|c|c|c|}
\hline \multirow[b]{2}{*}{ Fiscal year } & \multicolumn{10}{|c|}{ Health care service utilized; \% of patients receiving ("yes") and not receiving ("no") palliative care } \\
\hline & Yes & No & Yes & No & Yes & No & Yes & No & Yes & No \\
\hline 2004 & 99.9 & 99.9 & 93.2 & 95.6 & 69.3 & 58.4 & 16.5 & 44.5 & 8.2 & 31.9 \\
\hline 2005 & 99.9 & 99.8 & 94.0 & 95.9 & 69.9 & 59.0 & 18.5 & 45.9 & 10.2 & 33.8 \\
\hline 2006 & 99.9 & 99.8 & 94.8 & 96.1 & 72.9 & 64.5 & 19.7 & 45.6 & 11.2 & 35.5 \\
\hline 2007 & 99.9 & 99.6 & 95.4 & 96.1 & 75.2 & 67.5 & 24.0 & 47.4 & 16.0 & 37.5 \\
\hline 2011 & 99.8 & 99.3 & 96.8 & 96.3 & 78.7 & 72.0 & 28.6 & 52.1 & 20.8 & 43.6 \\
\hline 2012 & 99.8 & 99.3 & 97.2 & 96.2 & 78.9 & 71.6 & 30.2 & 52.5 & 21.9 & 44.7 \\
\hline 2013 & 99.8 & 99.2 & 97.2 & 96.1 & 80.5 & 73.2 & 31.4 & 54.6 & 23.6 & 46.9 \\
\hline 2014 & 99.8 & 99.2 & 97.3 & 96.4 & 80.6 & 73.3 & 31.5 & 53.8 & 24.2 & 46.5 \\
\hline $\begin{array}{l}\text { Absolute difference, \% } \\
(95 \% \mathrm{Cl})^{*}\end{array}$ & \multicolumn{2}{|c|}{$\begin{array}{c}0.3 \\
(0.3 \text { to } 0.3)\end{array}$} & \multicolumn{2}{|c|}{$\begin{array}{c}0.2 \\
(0.1 \text { to } 0.3)\end{array}$} & \multicolumn{2}{|c|}{$\begin{array}{c}10.2 \\
(10.0 \text { to } 10.5)\end{array}$} & \multicolumn{2}{|c|}{$\begin{array}{c}22.0 \\
(21.7 \text { to } 22.3)\end{array}$} & \multicolumn{2}{|c|}{$\begin{array}{c}20.1 \\
\text { (19.8 to 20.3) }\end{array}$} \\
\hline
\end{tabular}




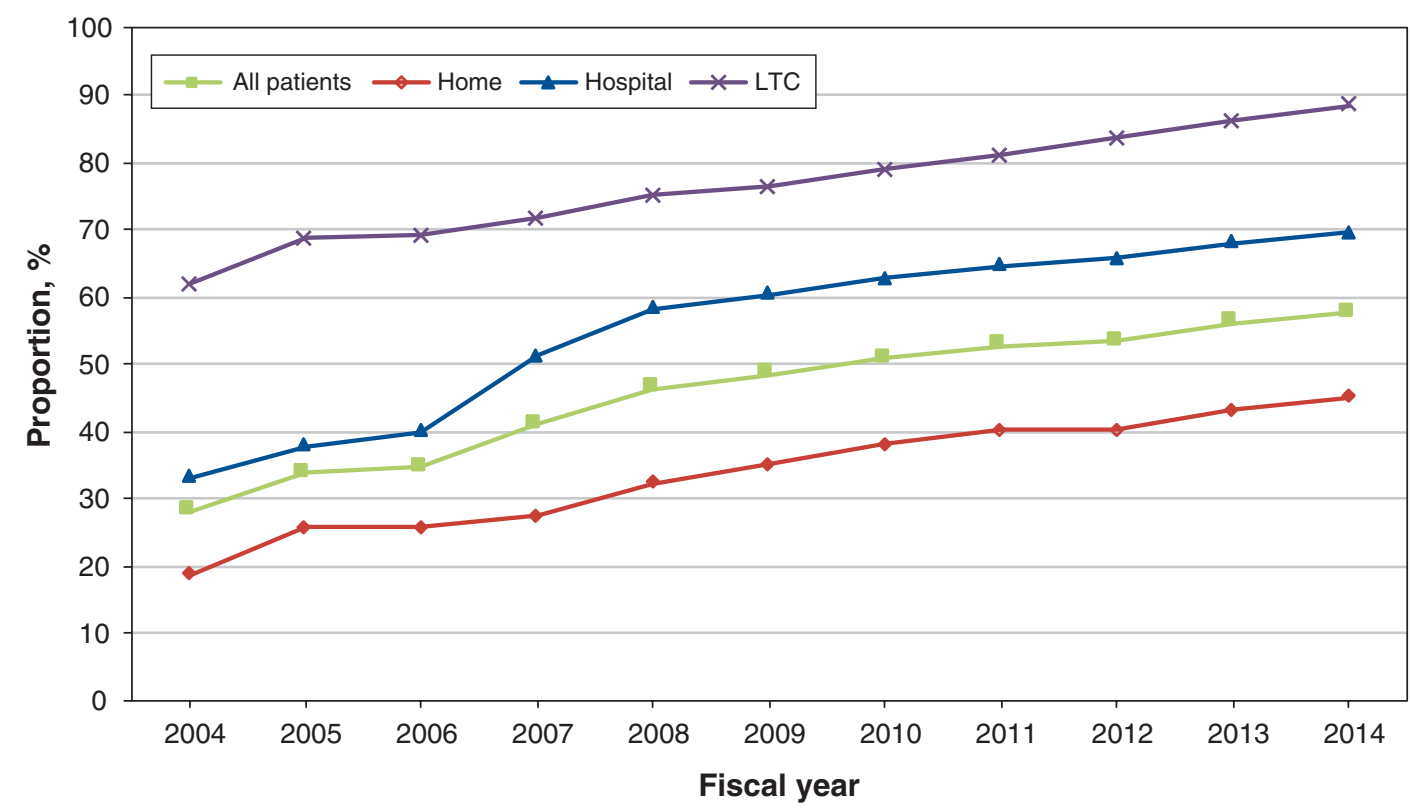

Figure 2: Temporal trends in proportion of patients receiving palliative care in the last 6 months of life, overall and by location of death, from Apr. 1, 2004, to Mar. 31, 2015 (fiscal year 2004 to fiscal year 2014). Note: LTC = long-term care.

\section{Limitations}

Our population-based observational study describes associations but cannot explain the causes for high rates of health care utilization near the end of life. In particular, we lacked information on several factors previously shown to be associated with the use of health services, for example, patient and family preferences, provider decision-making, and differential availability of hospice and palliative care services across various patient populations and geographic locations..$^{22,39-41}$ These factors may have important influences on decisions with respect to location of death. Furthermore, we have reported costs from the perspective of the health care system payer; therefore, we have not considered all societal costs, including out-of-pocket expenses and informal care costs. These latter costs may vary by chronic condition ${ }^{42}$ and can be a substantial burden on patients and informal care providers. ${ }^{42,43} \mathrm{We}$ used primarily physician billing codes to identify receipt of palliative care, so we likely underestimated the reported rates, particularly for care delivered in non-acute care settings and by non-physicians. ${ }^{17}$ It is also plausible that changes in coding practices over time might have affected our reported estimates. However, given the relatively short duration of our study and the lack of sharp spikes in year-to-year trends, we believe that such changes would have minimal effects on our results and the conclusions drawn.

\section{Conclusion}

In this population-based study, we found decreasing rates of deaths in hospital and a corresponding increase in the provision of palliative care to dying Canadians. However, other markers of end-of-life care did not change over time, with about three-quarters of decedents being admitted to hospital and about 1 in 5 being admitted to the ICU during the last 6 months of life. Rates of hospitalization before death were higher for those living in more rural and economically disadvantaged neighbourhoods. It is possible that increased capacity for palliative, hospice and home care at the end of life may help to better align health system resources with the preferences of most patients, a topic that should be explored in future studies.

\section{References}

1. Bekelman JE, Halpern SD, Blankart CR, et al. Comparison of site of death, health care utilization, and hospital expenditures for patients dying with cancer in 7 developed countries. 7AMA 2016;315:272-83.

2. Pivodic L, Pardon K, Morin L, et al.; EURO IMPACT. Place of death in the population dying from diseases indicative of palliative care need: a crossnational population-level study in 14 countries. 7 Epidemiol Community Health 2016;70:17-24.

3. Cohen J, Pivodic L, Miccinesi G, et al. International study of the place of death of people with cancer: a population-level comparison of 14 countries across 4 continents using death certificate data. Br 7 Cancer 2015;113:1397-404.

4. Gomes B, Calanzani N, Gysels M, et al. Heterogeneity and changes in preferences for dying at home: a systematic review. BMC Palliat Care 2013;12:7.

5. Gomes B, Higginson IJ, Calanzani N, et al.; PRISMA. Preferences for place of death if faced with advanced cancer: a population survey in England, Flanders, Germany, Italy, the Netherlands, Portugal and Spain. Ann Oncol 2012;23: 2006-15.

6. Heyland DK, Barwich D, Pichora D, et al.; ACCEPT (Advance Care Planning Evaluation in Elderly Patients) Study Team; Canadian Researchers at the End of Life Network (CARENET). Failure to engage hospitalized elderly patients and their families in advance care planning. FAMA Intern Med 2013;173:778-87.

7. Carstairs S, Beaudoin G. Quality end-of-life care: the right of every Canadian [report]. Ottawa: Standing Senate Committee on Social Affairs, Science and Technology; 2000. Available: https://sencanada.ca/content/sen/committee/ 362/upda/rep/repfinjun00-e.htm (accessed 2018 June 19). 
8. Schüklenk U, van Delden JJ, Downie J, et al. End-of-life decision-making in Canada: the report by the Royal Society of Canada expert panel on end-oflife decision-making. Bioethics 2011;25(Suppl 1):1-73.

9. Chapter 3, section 3.08: Palliative care. In: 2014 annual report of the Office of the Auditor General of Ontario. Toronto: Queen's Printer for Ontario; 2014:258-88. Available: www.auditor.on.ca/en/content/annualreports/arreports/en14/308 en14.pdf (accessed 2019 Feb. 11).

10. Wilson DM, Truman CD, Thomas R, et al. The rapidly changing location of death in Canada, 1994-2004. Soc Sci Med 2009;68:1752-8.

11. Gomes B, Calanzani N, Higginson IJ. Reversal of the British trends in place of death: time series analysis 2004-2010. Palliat Med 2012;26:102-7.

12. Mai TTX, Lee E, Cho H, et al. Increasing trend in hospital deaths consistent among older decedents in Korea: a population-based study using death registration database, 2001-2014. BMC Palliat Care 2018;17:16.

13. Sarmento VP, Higginson IJ, Ferreira PL, et al. Past trends and projections of hospital deaths to inform the integration of palliative care in one of the most ageing countries in the world. Palliat Med 2016;30:363-73.

14. Iezzoni LI, Heeren T, Foley SM, et al. Chronic conditions and risk of inhospital death. Health Serv Res 1994;29:435-60.

15. Garland A, Yogendran M, Olafson K, et al. The accuracy of administrative data for identifying the presence and timing of admission to intensive care units in a Canadian province. Med Care 2012;50:e1-6.

16. Scales DC, Guan J, Martin CM, et al. Administrative data accurately identified intensive care unit admissions in Ontario. 7 Clin Epidemiol 2006; 59:802-7.

17. Tanuseputro P, Budhwani S, Bai YQ, et al. Palliative care delivery across health sectors: a population-level observational study. Palliat Med 2017;31:247-57.

18. Seow H, O'Leary E, Perez R, et al. Access to palliative care by disease trajectory: a population-based cohort of Ontario decedents. BM7 Open 2018;8:e021147.

19. Wodchis WP, Bushmeneva K, Nikitovic M, et al. Guidelines on person-level costing using administrative databases in Ontario. Working Paper Series Vol 1. Toronto: Health System Performance Research Network; 2013 May. Available: www.hsprn.ca/uploads/files/Guidelines_on_PersonLevel_Costing May_2013.pdf (accessed 2018 May 23).

20. Wodchis WP, Austin PC, Henry DA. A 3-year study of high-cost users of health care. CMA7 2016;188:182-8.

21. Normand ST, Landrum MB, Guadagnoli E, et al. Validating recommendations for coronary angiography following acute myocardial infarction in the elderly: a matched analysis using propensity scores. 7 Clin Epidemiol 2001;54:387-98.

22. Seow H, Sutradhar R, McGrail K, et al. End-of-life cancer care: temporal association between homecare nursing and hospitalizations. 7 Palliat Med 2016;19:263-70.

23. Fassbender K, Fainsinger RL, Carson M, et al. Cost trajectories at the end of life: the Canadian experience. 7 Pain Symptom Manage 2009;38:75-80.

24. Chapter 1, section 1.08: Palliative care. In: 2016 annual report of the Office of the Auditor General of Ontario. Toronto: Queen's Printer for Ontario; 2016:98-108. Available: www.auditor.on.ca/en/content/annualreports/arreports/en16/ v2_108en16.pdf (accessed 2019 Feb. 11).

25. Heyland DK, Lavery JV, Tranmer J, et al.; Queen's/KGH End of Life Research Working Group. The final days: an analysis of the dying experience in Ontario. Ann R Coll Physicians Surg Can 2000;33:356-61.

26. Sinclair D, Rochon M, Leatt P. Riding the third rail: the story of Ontario's Health Services Restructuring Commission, 1996-2000. Montréal: Institute for Research on Public Policy; 2005 Aug. 15. Available: http://irpp.org/research-studies/ book-2005-08-15/ (accessed 2017 Feb. 27).

27. Lynch T, Connor S, Clark D. Mapping levels of palliative care development: a global update. 7 Pain Symptom Manage 2013;45:1094-106.

28. Local Health Integration Networks; Quality Hospice Palliative Care Coalition of Ontario. Advancing high quality, high value palliative care in Ontario: a declaration of partnership and commitment to action. Toronto: Queen's Printer for Ontario; December 2011. Available: http://health.gov.on.ca/en/public/ programs/ltc/docs/palliative\%20care_report.pdf (accessed 2017 Nov. 1).

29. Sutradhar R, Barbera L, Seow HY. Palliative homecare is associated with reduced high- and low-acuity emergency department visits at the end of life: a population-based cohort study of cancer decedents. Palliat Med 2017;31:448-55.

30. Seow H, Brazil K, Sussman J, et al. Impact of community based, specialist palliative care teams on hospitalisations and emergency department visits late in life and hospital deaths: a pooled analysis. BM7 2014;348:g3496.

31. Dumanovsky T, Augustin R, Rogers M, et al. The growth of palliative care in U.S. hospitals: a status report. 7 Palliat Med 2016;19:8-15.

32. Tanuseputro $\mathrm{P}$, Wodchis WP, Fowler R, et al. The health care cost of dying: a population-based retrospective cohort study of the last year of life in Ontario, Canada. PLoS One 2015;10:e0121759.

33. Einav L, Finkelstein A, Mullainathan S, et al. Predictive modeling of U.S. health care spending in late life. Science 2018;360:1462-5.

34. Wodchis WP, Arthurs E, Khan AI, et al. Cost trajectories for cancer patients. Curr Oncol 2016;23(Suppl 1):S64-75.

35. Pham B, Krahn M. End-of-life care interventions: an economic analysis. Ont Healtb Technol Assess Ser 2014;14:1-70.
36. Seow H, Pataky R, Lawson B, et al. Temporal association between home nursing and hospital costs at end of life in three provinces. Curr Oncol 2016;23(Suppl 1):S42-51.

37. Zimmermann C, Swami N, Krzyzanowska M, et al. Early palliative care for patients with advanced cancer: a cluster-randomised controlled trial. Lancet 2014;383:1721-30.

38. Rocker G, Downar J, Morrison RS. Palliative care for chronic illness: driving change. CMA7 2016;188:E493-8.

39. Hart JL, Harhay MO, Gabler NB, et al. Variability among US intensive care units in managing the care of patients admitted with preexisting limits on life-sustaining therapies. 7AMA Intern Med 2015;175:1019-26.

40. Obermeyer Z, Powers BW, Makar M, et al. Physician characteristics strongly predict patient enrollment in hospice. Health Aff (Millwood) 2015;34:993-1000.

41. Kelley AS, Ettner SL, Morrison RS, et al. Determinants of medical expenditures in the last 6 months of life. Ann Intern Med 2011;154:235-42.

42. Kelley AS, McGarry K, Gorges R, et al. The burden of health care costs for patients with dementia in the last 5 years of life. Ann Intern Med 2015; 163:729-36

43. Chai H, Guerriere DN, Zagorski B, et al. The magnitude, share and determinants of unpaid care costs for home-based palliative care service provision in Toronto, Canada. Health Soc Care Community 2014;22:30-9.

Affiliations: Departments of Critical Care Medicine (Hill, Scales, Rubenfeld, Wunsch, Dev, Fowler) and of Medicine (Gandhi, Berry), Sunnybrook Health Sciences Centre; Sunnybrook Research Institute (Hill); ICES (Stukel, Fu, Scales); Institute of Health Policy, Management and Evaluation (Stukel, Fowler), Interdepartmental Division of Critical Care (Scales, Rubenfeld, Wunsch, Dev, Fowler), Faculty of Medicine (Laupacis), Department of Anesthesia (Wunsch), Department of Medicine (Sinha, Gandhi, La Delfa), Division of Palliative Medicine, Department of Medicine (Zimmermann), and Division of Palliative Care, Department of Family Medicine, Faculty of Medicine (Myers), University of Toronto; Li Ka Shing Knowledge Institute (Laupacis) and Department of Palliative Care (La Delfa), St. Michael's Hospital, Toronto, Ont.; Departments of Medicine and Critical Care (Downar), Division of Palliative Care, University of Ottawa, Ottawa, Ont.; Divisions of Geriatric Medicine and Neurology (Rockwood), Department of Medicine, Dalhousie University, Halifax, NS; Department of Critical Care Medicine (Heyland), Queen's University, Kingston Ont.; Department of Medicine (Sinha) and Division of Palliative Care (Myers), Sinai Health System; Department of Medicine (Sinha), Division of Palliative Care, Department of Supportive Care (Zimmermann), and Ted Rogers Centre for Heart Research, Peter Munk Cardiac Centre (Ross), University Health Network, Toronto, Ont.; School of Population and Public Health (Kozak), University of British Columbia; Department of Family and Community Medicine (Kozak), Providence Health Care, Vancouver, BC

Contributors: All of the authors contributed to the conceptualization of this manuscript, including the design or analysis and interpretation of the data, drafting the article and revising the manuscript for important intellectual content. All of the authors gave final approval of the version to be published, and agreed to act as guarantors of the work.

Funding: The study was supported by a grant from the National Institute on Aging (US National Institutes of Health) P01-AG019783. James Downar is funded by an Associated Medical Services, Inc. Phoenix Fellowship. Kenneth Rockwood is funded by the Dalhousie University Medical Research Foundation Chair in Alzheimer Disease Research. Samir Sinha is funded by the Peter and Shelagh Godsoe Chair in Geriatrics. Camilla Zimmermann is funded by the Rose Family Chair in Supportive Care.

Supplemental information: For reviewer comments and the original submission of this manuscript, please see www.cmajopen.ca/content/7/2/ E306/suppl/DC1.

Disclaimer: This study was supported by ICES, which is funded by an annual grant from the Ontario Ministry of Health and Long-Term Care (MOHLTC). The opinions, results and conclusions reported in this article are those of the authors and are independent from the funding sources. No endorsement by ICES or the Ontario MOHLTC is intended or should be inferred. Parts of this material are based on data and/or information compiled and provided by the Canadian Institute for Health Information (CIHI). However, the analyses, conclusions, opinions and statements expressed in the material are those of the authors, and not necessarily those of CIHI. 